\title{
РОЛЬ ОРГАНИЗАЦИИ ОБЪЕДИНЕННЫХ НАЦИЙ В УРЕГУЛИРОВАНИИ НАГОРНО-КАРАБАХСКОГО КОНФЛИКТА
}

Аннотация: Статья посвящена рассмотрению вопросов, связанных с урегулированием одного из самых затяжных конфликтов на постсоветском пространстве, - нагорно-карабахского конфликта. На сегодняшний день усилия участников конфликта по его урегулированию явно недостаточны. Основным инструментом для разрешения вышеуказанного спора ялвяестя Минская группа ОБСЕ. В этой связи, роль такой универсальной организации как ООН значительно принижается. Автором анализируются решения Совета Безопасности касательно статуса Нагорного Карабаха, рекомендательнье резолючии Генеральной Ассамблеи ООН. Сформулирован вывод о том,что ООН следует прикладьвать больше усилий для мирного урегулирования спора и акцентировать внимание на действиях сторон конфликта вне рамок Минской группь ОБСЕ. Отмечена колоссальная роль ООН в реализации права народов на самоопределение для гарантирования прав и свобод человека. Вместе с тем стоит отметить, что в случае новой вспьики насилия, возобновления военных действий и окончательного провала мирных переговоров именно деятельность ООН, в лиие Совета Безопасности, вновь будет играть первостепенную роль.

Abstract: The article discusses issues related to the settlement of the Nagorno-Karabakh conflict-one of the most protracted conflicts in the former Soviet Union. To date, the efforts of the parties to the conflict to resolve it have clearly been insufficient. The main instrument for the resolution of this dispute is the Minsk Group of the Organization for Security and Co-operation in Europe. In this regard, the role of such all-inclusive organizations such as the United Nations has been significantly reduced. The author analyzes the decisions of the Security Council on the status of Nagorno-Karabakh as well as the non-binding resolutions of the UN General Assembly. The author determines that the UN should make a greater effort towards a peaceful settlement of the dispute and focus on the actions of the parties to the conflict outside the parameters of the OSCE Minsk Group. The article highlights the immense role of the UN in implementing the right of peoples to self-determination so as to safeguard their rights and freedoms. However, it is worth noting that if there is a new outbreak of violence, a resumption of hostilities and a definitive collapse of the peace talks, the UN, by way of the Security Council, will once again play a major role.

Ключевые слова: Нагорно-Карабахский конфликт, мирное урегулирование спора, деятельность ООН, право на самоопределение, резолючии Совета Безопасности, Армения и Азербайджан, непризнанная республика, Генеральная Ассамблея ООН, агрессия, приниип территориальной иелостности

Keywords: Nagorno-Karabakh conflict, peaceful settlement of the dispute, activities of the UN, right to self-determination, Security Council resolutions, Armenia and Azerbaijan, unrecognized republic, UN General Assembly, aggression, principle of territorial integrity

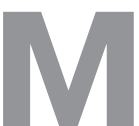

еждународное сообщество, представленное не только государствами, но и международными правительственными организациями различных уровней, должно предпринимать все необходимые меры с целью разрешения спорных проблем между сторонами этнополитических конфликтов при соблюдении всеми заинтересованными субъектами основополагающих принципов и иных норм международного права. На примере опыта урегулирования нагорно-карабахского конфликта проанализируем роль Организации Объединенных Наций $(\mathrm{OOH})$ в этом процессе.
Необходимо отметить, что довольно длительное время нагорно-карабахский конфликт не привлекал внимания мировой общественности. По мнению Э.Абдуллаева, это было связано с тем, что конфликт выступал в качестве одного из многочисленных факторов, ускоряющих процесс распада СССР, и устранение этой проблемы могло препятствовать разрушительным процессам, происходящим внутри Советского Союза ${ }^{[1]}$. В разгар конфликта времени появлялись определенные резолюции, заявления ООН, Европейского Союза, но в этих документах не содержалась точная оценка 
DOI: $10.7256 / 1811-9018.2013 .11 .10076$

При цитировании этой статьи сноска на dоі обязательна

\section{Право и политика $11(166) \cdot 2013$}

действительных причин конфликта, в них не было никакого различия между агрессором и стороной, подвергшейся агрессии.

В 1992 году, став членом ООН, Азербайджан обратился к этой организации с просьбой выразить отношение к агрессивной политике Армении и предотвратить ее захватнические действия. На основе этого обращения делегация ООН совершила поездку в регион и представила соответствующие сведения об этом Генеральному секретарю ООН. Генеральный секретарь ООН, в свою очередь, выразил поддержку усилий СБСЕ (Совещание по Безопасности и Сотрудничеству в Европе, с января 1995 года было переименовано на ОБСЕ - Организация по Безопасности и Сотрудничеству в Европе) и готовность оказать содействие этой организации для достижения соответствующих результатов.

12 мая 1992 года Совет Безопасности ООН, обсудив проблему Нагорного Карабаха, ограничился заявлением об этом. В распространенном от имени председателя Совета Безопасности заявлении выражалось беспокойство в связи с ухудшением положения в Нагорном Карабахе и подчеркивалась необходимость оказания срочной помощи вынужденным переселенцам. Единственным положительным шагом Совета Безопасности ООН стало то, что письмо постоянного представительства Азербайджана при ООН, адресованное председателю Совета Безопасности было распространено в качестве официального документа СБ. В этом письме боевые действия, проводимые Арменией, оценивались как попытка нарушения территориальной целостности суверенного государства.

Армения, в свою очередь, предпринимала ответные шаги. Так, в августе 1992 года по обращению Армении было созвано новое заседание Совета Безопасности $\mathrm{OOH}$ и распространено новое заявление его председателя. И в этом документе стороны призывались к прекращению огня, и выражалось беспокойство $\mathrm{OOH}$ в связи с обострением ситуации.

В 1993 году армяне оккупировали район Азербайджана - Кяльбаджар. В этой связи Азербайджан обратился к $\mathrm{OOH} \mathrm{с} \mathrm{просьбой} \mathrm{дать} \mathrm{оценку} \mathrm{действиям}$ агрессора. 6 апреля было принято заявление председателя Совета Безопасности ООН, в котором выражалось беспокойство в связи с ростом напряженности между Арменией и Азербайджаном, вторжением «местных армянских сил» в Кяльбаджарский район. В заявлении вновь подтверждался принцип неприкосновенности территориальной целостности всех государств и вновь находил свое отражение призыв к сторонам делать соответствующие шаги для достижения продвижения в мирном процессе в рамках СБСЕ. Следует отметить, что это заявление было составлено, в основном, по данным, представленным Арменией, которая старалась доказать виновность «местных армян» в захвате этого района.

30 апреля 1993 года была принята первая резолюция Совета Безопасности ООН по нагорно-карабахскому конфликту. Этот документ под названием «Резолюция Совета Безопасности ООН № 822» был подготовлен со ссылкой на заявления председателя Совета Безопасности от 29 января и 6 апреля 1993 года. В документе говорилось: «Совет Безопасности...будучи обеспокоен тем, что эта ситуация угрожает миру и безопасности в регионе, выражая серьезную обеспокоенность в связи с перемещением большого числа гражданских лиц и чрезвычайной гуманитарной ситуацией в регионе, в частности в Кяльбаджарском районе, вновь подтверждая уважение суверенитета и территориальной целостности всех государств в регионе, вновь подтверждая также нерушимость международных границ и недопустимость применения силы для приобретения территории, заявляя о своей поддержке мирного процесса, осуществляемого в рамках Совещания по безопасности и сотрудничеству в Европе, и будучи глубоко обеспокоен разрушительными последствиями, которые может иметь для этого процесса эскалация вооруженных военных действий:

- требует немедленного прекращения всех военных действий и враждебных актов в целях установления прочного прекращения огня, а также немедленного вывода всех оккупирующих сил из Кяльбаджарского района и других, недавно оккупированных районов Азербайджана;

- $\quad$ настоятельно призывает заинтересованные стороны немедленно возобновить переговоры в целях разрешения конфликта в рамках мирного процесса Минской группы Совещания по безопасности и сотрудничеству в Европе и воздерживаться от любых действий, которые затруднят мирное решение проблемы» ${ }^{[2]}$.

В целом резолюция содержала довольно много общих фраз и не указаны конкретные пути решения конфликта.

Тем не менее, в современной международной жизни резолюции Совета Безопасности ООН относятся к числу важнейших документов. В самый разгар войны в Карабахе, с 30 апреля по 12 ноября 1993 г., были приняты четыре резолюции Совета Безопасности ООН (822, $853,874$ и 884) $)^{1}$, который призвал стороны к прекраще-

\footnotetext{
${ }^{1}$ Подробнее см.: Резолюция Совета Безопасности Организации Объединенных Наций №822 от 30 апреля 1993 г. (Резолюция СБ
} 
нию военных и враждебных действий, к выводу войск с контролируемых территорий при обеспечении безопасности армянского населения Нагорного Карабаха, прекращению блокады и т.п., чтобы, тем самым, разрядить вооруженную стадию конфликта, перевести его урегулирование в мирное русло. Резолюции содержат, в частности, следующие положения:

- серьезную обеспокоенность в связи с эскалачией вооруженных военных действий, и в частности вторжением местных армянских сил в сопредельные с Нагорным Карабахом районы Азербайджана;

- серьезную обеспокоенность в связи с перемещением большого числа гражданских лиц и чрезвычайной гуманитарной ситуацией в регионе;

- уважение суверенитета и территориальной целостности всех государств в регионе,

- немедленного прекращения всех военных действий и вывода всех оккупируюших сил из оккупированных районов Азербайджана;

- $\quad$ призыв к заинтересованным сторонам немедленно возобновить переговоры в иелях разрешения конфликта в рамках мирного процесса Минской группь Совещания по безопасности и сотрудничеству в Европе;

- призыв к правительству Республики Армении продолжать оказывать свое влияние в иелях обеспечения соблюдения армянами Нагорного Карабаха положений резолюиий СБ ООН и принятия этой стороной предложений Минской группы;

- призыв к государствам - членам ООН воздерживаться от поставок любого оружия и военного имущества;

- осуждение всех враждебных действий в регионе, в частности нападений на гражданских лии, бомбардировки и артиллерийские обстрель населенных районов;

- осуждение эскалации военных действий вследствие нарушения прекращения огня и чрезмерного применения силь в ответ на эти нарушения.

Важно помнить, что уяснение и понимание содержания резолюций Совета Безопасности $\mathrm{OOH}$ невозможны без учета реалий обстановки, в которых

ООН 822 /1993/); Резолюция Совета Безопасности Организации Объединенных Наций №853 от 29 июля 1993 г. (Резолюция СБ ООН 853 /1993/); Резолюция Совета Безопасности Организации Объединенных Наций №874 от 14 октября 1993 г. (Резолюция СБ ООН 874 /1993/); Резолюция Совета Безопасности Организации Объединенных Наций №884 от 12 ноября 1993 г. (Резолюция СБ ООН 884 /1993Г) //Базы данных Организации Объединенных Наций http://www.un.org/ru/databases/ они принимались. Рассматриваемые документы были приняты в период с апреля по ноябрь 1993 года, то есть в самый разгар войны в Нагорном Карабахе и близлежащих районах. Тогда первоочередным и главнейшим требованием мирового сообщества, обращенным к участникам конфликта, было незамедлительное прекращение военных действий и иных враждебных актов. Именно это требование красной нитью проходит через все 4 резолюции.

Совет Безопасности ООН выдвинул это требование еще 30 апреля 1993 года в первой резолюции - Резолюции 822, но о его выполнении говорилось и в последующих резолюциях. Еще год в регионе шла война, как Арменией, так и Азербайджаном нарушались нормы международного гуманитарного права, увеличивался поток беженцев и вынужденных переселенцев. Но ведь «незамедлительность» прекращения огня не подразумевала отсрочки выполнения этого требования, в связи с чем сторона - нарушитель этого требования должна была, согласно резолюциям, нести особую ответственность за игнорирование воли международного сообщества.

Анализируя перечисленные документы, важно обратить внимание на их международно-правовой статус. В соответствии с Уставом ООН, Совету Безопасности $\mathrm{OOH}$ предоставлены широкие полномочия для разрешения спорных вопросов, в том числе и для урегулирования конфликтов. В случае, если вопрос приобретает характер угрозы миру, Совет Безопасности вправе принимать принудительные решения. Резолюции Совета Безопасности ООН обязательны для государств-членов, как правило, составляются на компромиссной основе. Неприемлем выборочный подход к ним, то есть недопустимо выполнять или требовать выполнения только тех положений, которые соответствуют интересам той или иной стороны конфликта. Принципиально значимо своевременное выполнение всех положений резолюции без каких-либо изъятий.

Однако на примере нагорно-карабахского конфликта этого не произошло, хотя акты агрессии создали серьезную угрозу региональной безопасности. Для прекращения конфликта можно было воспользоваться реальными механизмами давления, однако международное сообщество этого не сделало.

Определение понятия агрессии было дано Генеральной Ассамблеей ООН в резолюции 3314 (XXIX) от 14 декабря 1974 года ${ }^{[3]}$. Согласно этой резолюции, агрессией является применение вооруженной силы государством против суверенитета, территориальной неприкосновенности или политической независимости другого государ- 
DOI: 10.7256/1811-9018.2013.11.10076

При цитировании этой статьи сноска на доі обязательна

\section{Право и политика $11(166) \cdot 2013$}

ства, или каким-либо другим образом, несовместимым с Уставом Организации Объединенных Наций. Согласно ст. 3 резолюции, к актам агрессии относятся:

- $\quad$ вторжение или нападение вооруженных сил государства на территорию другого государства или любая военная оккупация, какой бы временный характер она ни носила, являющаяся результатом такого вторжения или нападения, или любая аннексия с применением силы территории другого государства или части ее;

- $\quad$ бомбардировка вооруженными силами государства территории другого государства или применение любого оружия государством против территории другого государства;

- $\quad$ блокада портов или берегов государства вооруженными силами другого государства;

- $\quad$ нападение вооруженными силами государства на сухопутные, морские или воздушные силы, или морские и воздушные флоты другого государства;

- применение вооруженных сил одного государства, находящихся на территории другого государства по соглашению с принимающим государством, в нарушение условий, предусмотренных в соглашении, или любое продолжение их пребывания на такой территории по прекращению действия соглашения;

- действие государства, позволяющего, чтобы его территория, которую оно предоставило в распоряжение другого государства, использовалась этим другим государством для совершения акта агрессии против третьего государства;

- $\quad$ засылка государством или от имени государства вооруженных банд, групп, иррегулярных сил или наемников, которые осуществляют акты применения вооруженной силы против другого государства, носящие столь серьезный характер, что это равносильно перечисленным выше актам, или его значительное участие в них.

За ту или иную форму акта агрессии государство-агрессор несет ответственность перед Советом Безопасности ООН, что дает последнему полномочия по принятию принудительных мер. Акты агрессии имели место со стороны и Азербайджана, и Армении, однако международное сообщество ре предприняло решительных мер для предотвращения этих действий.

Характерно, что в период, последовавший за принятием рассматриваемых резолюций Совета Безопасности $\mathrm{OOH}$, их выполнения чаще и настойчивей требовал Азербайджан, однако лишь в той их части, где говорится о «немедленном», «полном» и «безоговорочном» выводе оккупационных сил из районов Азербайджана, занятых армяно-карабахскими войсками, и возвращении туда своих беженцев. По справедливому утверждению В.Н. Казимирова, «Азербайджан, по сути, сводит требования резолюций к освобождению оккупированных территорий. Никакие другие требования в Баку не акцентируются, просто замалчиваются. Ему надо привлечь внимание к оккупации - тяжкому последствию вооруженного конфликта, к боли вынужденных переселенцев. Но этим самым хотят также оттеснить на второй план, сдвинуть на «потом» устранение главной спорной проблемы и причины конфликта-определение статуса Нагорного Карабаха» ${ }^{[4]}$.

После первых договоренностей об ограничении военных действий, отказа Азербайджана их продлить и последовавшего за этим взятия армянами Агдама Резолюция Совета Безопасности ООН 853 от 29 июля 1993 года призвала стороны «достичь прочных договоренностей о прекращении огня и соблюдать их», «срочно возобновить соблюдение прекращения огня, установленного в результате прямых контактов, предпринимаемых при содействии правительства Российской Федерации в поддержку Минской группы». Фактическое, а не декларируемое прекращение огня между участниками нагорно-карабахского конфликта с 12 мая 1994 года было достигнуто уже не столько благодаря указанным резолюциям, сколько благодаря посредничеству России и заявлению Совета глав государств-членов СНГ от 15 апреля 1994 года, впервые вознесшего требование о прекращении кровопролития в главный приоритет урегулирования конфликта. Соглашение о прекращении огня было не временным, а бессрочным (по умолчанию), и подписано не двумя, как ранее (Азербайджан, Нагорно-Карабахская Республика), а тремя сторонами конфликта (в том числе Арменией).

В связи с тем, что Азербайджан 19 мая 1992 года отказался участвовать в Минской конференции СБСЕ, пока армяне не оставят Шушу и Лачин, Совет Безопасности ООН предлагал «немедленно возобновить переговоры... в рамках мирного процесса Минской группы» (Резолюция 822), настоятельно призывал воздерживаться от любых действий, мешающих мирному разрешению конфликта, и «продолжать переговоры в рамках Минской группы, а также посредством прямых контактов» (Резолюция 853), призывал к скорому созыву Минской конференции (Резолюция 874). Переговоры в рамках Минской группы СБСЕ/ОБСЕ были затем продолжены, а прямые контакты с Нагорным Карабахом, вопреки трем резолюциям Совета Безопасности ООН, Азербайджан в конце 1993 года полностью прекратил. 
DOI: 10.7256/1811-9018.2013.11.10076

При цитировании этой статьи сноска на dоі обязательна

Международное право в XXI веке

Отдельным пунктом во всех рассматриваемых резолюциях проходит тезис об ухудшении отношений и напряженности между Азербайджаном и Арменией. Ни в одной из них Армения не отмечалась как противоборствующая сторона. Ей адресовались призывы «продолжать оказывать» или «использовать свое влияние» на армян Нагорного Карабаха (резолюции 853, 884). Нагорный Карабах по смыслу проходит как участник конфликта, хотя называется - как и Азербайджан - то «заинтересованной стороной», то просто «стороной» (резолюции 853, 874, 884). Иначе говоря, косвенным образом резолюции подводят к мысли о том, что нагорно-карабахский конфликт по конфигурации является все же трехсторонним.

В указанных резолюциях затронуты и другие аспекты конфликта, в том числе гуманитарные, например:

Совет Безопасности ООН «призывает (здесь и далее выделено в документе) обеспечить беспрепятственное осуществление международной деятельности по оказанию гуманитарной помощи в регионе» (Резолюция 822);

Совет Безопасности ООН «просит Генерального секретаря и соответствующие международные учреждения предоставить чрезвычайную гуманитарную помощь пострадавшему гражданскому населению и помочь беженцам и перемещенным лицам вернуться в свои дома с достоинством и в условиях безопасности» (Резолюция 874).

Итак, можно сделать следующие выводы относительно выполнения нагорно-карабахских резолюций Совет Безопасности ООН участниками конфликта:

- во-первых, Азербайджан в течение длительного времени не выполнял самое важное требование всех четырех резолюций - прекращение огня. Азербайджанская сторона не отказалась от враждебных актов, не желала прекращать боевые действия, продолжала делать ставку на силовое решение конфликта. Все это отрицательно повлияло и на выполнение других требований, в том числе другими участниками конфликта. Судя по всему, не намерен выполнять Баку эти резолюции и сейчас в части прекращения враждебных актов, восстановления экономических, транспортных и энергетических связей в регионе, прямых контактов с Нагорным Карабахом, созыва Минской конференции ОБСЕ;

- во-вторых, Армения практически не отреагировала на призыв мирового сообщества оказывать «сдерживающее» влияние на Нагорный Карабах, и в настоящее время не акцентирует внимания на нем в переговорном процессе;

- в-третьих, Армения и Нагорный Карабах продолжают не выполнять требования вывода оккупирующих сил из районов Азербайджана за пределами НК под предлогом необходимости «пакетного», всеобъемлющего урегулирования ${ }^{[5]}$.

Достичь полномасштабного осуществления проанализированных выше резолюций можно лишь при безусловной реализации взаимных обязательств сторонами нагорно-карабахского конфликта. В настоящее время каждая из сторон представляет мировому сообществу собственную трактовку причин и сути конфликта.

По нашему мнению, следует согласиться с В.Н. Казимировым, который отметил: «Невозможно считать резолюции СБ ООН по Карабаху выполненными, а позиции сторон в конфликте адекватными им. Показательно, что СБ ООН не стал больше принимать резолюций по этому конфликту, ибо их невыполнение сторонами подрывает его авторитет» ${ }^{[4]}$.

По нашему мнению, на сегодняшний день усилия участников конфликта по его урегулированию явно недостаточны. Международному сообществу надо поставить перед сторонами вопрос: готовы ли они признать статус Нагорного Карабаха спорной проблемой? Именно с целью решения этого вопроса и должны вестись переговоры. Акцентирование внимания сторон на других аспектах, более выгодных им, не приведет к урегулированию ситуации. Конфликт начался не с оккупации, а с военных действий, которые и привели к оккупации территории.

По проблеме нагорно-карабахского конфликта высказалась и Генеральная Ассамблея ООН. 14 марта 2008 года на 62-й сессии Генеральной Ассамблеи была принята резолюция «Положение на оккупированных территориях Азербайджана» ${ }^{[6]}$.

Накануне заседания Армения усилила нажим на Азербайджан. Ереван выступил с ультиматумом об отказе от переговоров по урегулированию нагорнокарабахского конфликта, если Баку будет настаивать на принятии в ООН резолюции, касающейся «оккупированных территорий Азербайджана». И это, в известной степени, способствовало тому, чтобы соответствующий документ тогда не прошел. На это решение повлияло и то, что три сопредседателя Минской группы ОБСЕ, (США, Россия и Франция) которые, как известно, являются и постоянными членами Совета Безопасности $\mathrm{OOH}$, выразили отрицательное отношение к обсуждению этого вопроса в $\mathrm{OOH}$.

Между тем, резолюции Генеральной Ассамблеи $\mathrm{OOH}$, хоть и носят рекомендательный характер, но когда вопрос попадает в повестку дня сессии, он уже с повестки не снимается. На одной из последующих сессий ГА ООН обязательно должна вернуться к этому вопросу, причем 
DOI: $10.7256 / 1811-9018.2013 .11 .10076$

При цитировании этой статьи сноска на dоі обязательна

\section{Право и политика $11(166) \cdot 2013$}

независимо от того, изменит или нет инициатор вопроса его формулировку. Это и произошло 14 марта 2008 года на 62-й сессии Генеральной Ассамблеи ООН.

Документ был принят 39 голосами «за» при семи «против». В голосовании участвовали 147 из 192 странчленов ООН. Сто государств-членов ООН воздержались при голосовании по резолюции об оккупированных территориях Азербайджана, который просит подтвердить свое право на Нагорный Карабах и прилегающие территории. Резолюцию, подтверждающую территориальную целостность Азербайджана, поддержали в том числе Сербия, Грузия и Украина.

Генеральная Ассамблея ООН заявила о неизменном уважении и поддержке суверенитета и территориальной целостности Азербайджанской Республики в пределах ее международно-признанных границ. В документе подчеркивается необходимость «немедленного, полного и безоговорочного вывода всех армянских сил со всех оккупированных территорий Азербайджанской Республики». «Ни одно государство не должно признавать законной ситуацию, сложившуюся в результате оккупации территорий Азербайджанской Республики, и не должно содействовать или способствовать сохранению этой ситуации», - говорится в принятой резолюции ${ }^{[6]}$.

В резолюции выражается серьезная озабоченность тем, «что вооруженный конфликт в нагорно-карабахском регионе Азербайджанской Республики и вокруг него продолжает создавать угрозу международному миру и безопасности» и негативно сказывается на гуманитарной ситуации в странах южного Кавказа. Генеральная Ассамблея подтверждает «неотъемлемое право населения, изгнанного с оккупированных территорий Азербайджанской Республики, на возвращение в свои дома и подчеркивает необходимость создания надлежащих условий для этого возвращения, включая всеобъемлющую реабилитацию пострадавших от конфликта территорий».

Выступая на заседании Генеральной Ассамблеи ООН от имени сопредседателей Минской группы Организации по безопасности и сотрудничеству в Европе (ОБСЕ) - США, Франции и России - представитель Соединенных Штатов Алехандро Вулфф заявил, что они не поддерживают эту резолюцию. По мнению сопредседателей, документ не отражает всех подходов к урегулированию конфликта, предложенных Минской группой в виде «сбалансированного пакета» в 2007 году. «К сожалению, в предложенной нашему вниманию резолюции выборочно отражена лишь часть из этих принципов. Другая часть исключена. В связи с таким селективным подходом наши три государства вынуждены выступить против этого одностороннего документа», - подчеркнул Алехандро Вулфф ${ }^{[7]}$.

Минская группа ОБСЕ была создана в 1992 году для поиска путей мирного урегулирования армяноазербайджанского конфликта. В 1997 году Минская группа ОБСЕ создала новый формат для переговоров, состоящих из трех сопредседателей - США, Франции и России. Более подробно деятельность Минской группы будет рассмотрена далее.

Следует отметить, что вопрос о Нагорном Карабахе обсуждался в рамках ООН и позднее. Так, на 65-й сессии Генеральной ассамблеи ООН в ноябре 2010 года состоялись обсуждения по пункту повестки «право народов на самоопределение», в ходе которых с речами выступили представители делегаций примерно 40 стран и международных организаций. В частности, в обсуждениях приняла участие и Армения, которая подчеркнула, что попрание этого права приводит к трагическим последствиям, войне и разрушениям. В Карабахе армянский народ боролся за свое право на свободу, противостоя развязанной против него войне и всем попыткам уничтожить его на своей же родине. Народ Нагорного Карабаха, реализуя право наций на самоопределение, сделал свой выбор в пользу суверенитета и для достижения этой цели использовал все правовые механизмы. Он также отметил важность роли ООН и реализации права наций и народов на безоговорочное и постоянное самоопределение для гарантирования мандата.

В настоящий момент Нагорно-Карабахская Республика не получила признания со стороны государств-членов ООН и не является ее участником; в связи с этим в официальных документах государств-членов ООН и образованных ими организациях по отношению к НКР не употребляются некоторые политические категории (президент, премьер-министр, выборы, правительство, парламент, флаг, герб, столица).

На сегодняшний день главную ответственность за урегулирование нагорно-карабахского конфликта несет ОБСЕ. ООН в лице Совета Безопасности и других органов неизменно высказывается в поддержку деятельности ОБСЕ, а так же двусторонних и иных усилий на разных уровнях в пользу скорейшего урегулирования нагорно-карабахского конфликта. Но на этом ее роль практически заканчивается. Вместе с тем стоит отметить, что в случае новой вспышки насилия, возобновления военных действий и окончательного провала мирных переговоров именно деятельность $\mathrm{OOH}$, в лице Совета Безопасности, вновь будет играть первостепенную роль. 
DOI: 10.7256/1811-9018.2013.11.10076

При цитировании этой статьи сноска на dоі обязательна

Международное право в XXI веке

\section{Библиография:}

1. Абдуллаев, Э. Проблема Нагорного Карабаха в контексте международного права. [Текст] / Э. Абдуллаев; - Баку, 2005.-С. 120.

2. Казимиров, В. Карабах и резолюции Совета Безопасности ООН // Информационное агентство REGNUM. [Электронный ресурс] : http://www. vn.kazimirov.ru/k100.htm Дата обращеня : 12.10.2013 г.

3. Вартанян, А.С. Проблема урегулирования конфликта в Нагорном Карабахе и роль международных организаций [Текст] : автореф. дисс... канд. пол. наук : 23.00 .04 - Политические проблемы международных отношений, глобального и регионального развития / Вартанян Артем Сергеевич - Москва, 2011.-С. 12.

4. Сазонова К.Л. «Большая пятерка» и миротворческая деятельность Организации Объединенных Наций: политические и правовые вызовы и угрозы // NB: Международное право. - 2013. - 2. - C. 1-15. URL: http://www.e-notabene.ru/wl/article_4769.html

5. Алейников А.В. Системные конфликты в России: концептуальные основания анализа. Статья 1. // NB: Проблемы общества и политики. - 2013.-7.- С. 94-140. URL: http://www.e-notabene.ru/pr/article_2306.html

\section{References (transliteration):}

1. Abdullaev, E. Problema Nagornogo Karabakha v kontekste mezhdunarodnogo prava. [Tekst] / E. Abdullaev; - Baku, 2005.-S. 120.

2. Kazimirov, V. Karabakh i rezolyutsii Soveta Bezopasnosti OON // Informatsionnoe agentstvo REGNUM. [Elektronnyi resurs] : http://www.vn.kazimirov.ru/ k100.htm Data obrashchenya : 12.10.2013 g.

3. Vartanyan, A.S. Problema uregulirovaniya konflikta v Nagornom Karabakhe i rol' mezhdunarodnykh organizatsii [Tekst] : avtoref. diss... kand. pol. nauk : 23.00.04 - Politicheskie problemy mezhdunarodnykh otnoshenii, global'nogo i regional'nogo razvitiya / Vartanyan Artem Sergeevich - Moskva, 2011. - S. 12.

4. Sazonova K.L. «Bol'shaya pyaterka» i mirotvorcheskaya deyatel'nost' Organizatsii Ob' 'edinennykh Natsii: politicheskie i pravovye vyzovy i ugrozy // NB: Mezhdunarodnoe pravo. - 2013. - 2. - C. 1-15. URL: http://www.e-notabene.ru/wl/article_4769.html

5. Aleinikov A.V. Sistemnye konflikty v Rossii: kontseptual'nye osnovaniya analiza. Stat'ya 1. // NB: Problemy obshchestva i politiki. - 2013. - 7. - C. 94-140. URL: http://www.e-notabene.ru/pr/article_2306.html 